\title{
ANALYSIS OF STUDY RESULTS AND THE USE OF E-LEARNING MATERIALS WITHIN DISTANCE EDUCATION
}

\section{Renáta Kunstová}

\section{Abstract}

This paper summarizes the results of analysis which concerns new opened field of study with distance mode of study. The aim of analysis is to evaluate the comparability of full-time and distance mode of study and to answer three research questions. The first question concerns the characteristics of distance students who unsuccessfully ended their study already after the second semester. The second research question focuses on utilization of online tests and lists of control questions. The third question investigates how important are video records of lectures for distance students. The analysis is based on data obtained from the Integrated Study Information System. Results should be taken into account in the coming years, when lecturers will update e-learning study materials and prepare tutorials.

\section{Key Words}

activity monitoring, distance mode of study, e-learning, higher education, interactive element, online test, video record of lecture
University of Economics, Prague

kunstova@vse.cz

ARTICLE INFO

Article type

Full research paper

doi: 10.7160/eriesj.2012.050401

Article history

Received: August 3, 2012

Received in revised form: October 11, 2012

Accepted: October 23, 2012

Available on-line: December 30, 2012

Kunstová, R. (2012) "Analysis of Study Results and the Use of e-Learning Materials within Distance Education", Journal on Efficiency and Responsibility in Education and Science, Vol. 5, No. 4, pp. 185-194, ISSN 1803-1617, [on-line] www.eriesjournal.com/_papers/article_179.pdf 


\section{Introduction}

Current trends in information and communication technologies allow to create new business models with greater emphasis on human capital. New working environment modifies requirements for skills and education. According to the report of the Ministry of Education, Youth and Sports published in September 2012 (MEYS, 2012), the Czech tertiary education system offers within bachelor's and master's degree programmes over nine thousand field of studies. Most of them are offered in a full-time or a part-time mode of study, only four of them allow a distance mode of study. It means that although distance education has a long history, as a mode of study within a higher education is not currently usual in the Czech Republic.

This paper focuses on the field of study "Business Informatics" with distance mode of study which is offered within master's degree program at the University of Economics in Prague, Faculty of Informatics and Statistics. Its accreditation was the response to the growing demand from students. Students of informatics specialisations often start to work during their bachelor's degree and some of them leave the university after that. If their professional growth requires master's degree of study and they cannot leave their jobs, distance education happens to be a very convenient option for them.

Each field of study of any degree programme are subject to accreditation awarded by the Ministry of Education, Youth and Sports. The Accreditation Commission determines whether submitted field of study meets all requirements before the approval. The accreditation process is periodically repeated. Implementation of distance education had to be therefore very carefully monitored and its quality continually evaluated during the entire period of its accreditation. Jung et al (2011, p. 80) argues that "with the convergence of conventional and distance educational methods, there should be no distinctions between quality assurance in distance education and conventional education or between e-learning and face-to-face teaching".

Distance education has experienced dramatic growth since the early 1980s and has many definitions. The most often is cited Holmberg's (1986) definition from his book titled "Growth and Structure of Distance Education":

"Distance education includes the various forms of study at all levels which are not under the continuous immediate supervision of tutors present with their students in lecture rooms or on the same premises, but which, nevertheless, benefit from the planning, guidance and tuition of a tutorial organization."

Various forms of study, mentioned in the definition, also mean different methods of learning. Used methods changed from early correspondence courses, using primarily print-based materials, to courses with interactive materials accessible via information systems and information and communication technologies. New methods are based on Internet and multimedia technologies which make learning more attractive.

Online learning, which is a part of distance education, was the subject of many research studies. The Center for Technology in Learning performed (2010) a meta-analysis of the research literature from 1996 through July 2008 containing more than thousand empirical studies of online learning. The meta-analysis compared results of reviewed studies in differences between online and a face-to-face learning, in measuring of students' learning outcomes and in using of rigorous research design. One of the key findings was that "students in online conditions performed modestly better, on average, than those learning the same material through traditional face-to-face instruction" ( $p$. xiv), combination of online and a face-to-face learning brought the best results. These positive results correspond to growing 
trends in supporting face-to-face education by online learning and in implementation of distance education.

Carnwell (2000) investigated relationships among approaches to study, learning styles and materials design and how these approaches impacted students' need in a distance learning support. He argues that study material design influences the guidance and the support required by students. It is confirmed by Murphy and Rodríguez-Manzanares (2008), who found that an absence of body language and visual presence of teacher require to find new ways of interacting. This information corresponds to results of study (Houška, 2011), that the output knowledge of distance students without a special study material is worse than students who attended lectures. Therefore it is not surprising that interactive elements are necessary condition of well-prepared distance study material which is submitted to the Accreditation Commission.

This paper builds on the work of the author which was published as a contribution of the conference ERIE 2012 (Kunstová, 2012). The contribution was focused on interactive elements of e-learning materials. It contained analyses of using these interactive elements during winter semester 2011. This paper is extended by a data analysis from the next period (summer semester 2012) and by a comparison of results in both monitored periods. Data were obtained from the Integrated Study Information System. Because the first students were admitted in September 2011, data only from two periods are available. Although data sample is small, the results are very important for a managing of further distance education.

\section{Materials and Methods}

The comparability of distance and full-time education is based on the criteria that students' output knowledge has to be the same whether a course is taken online or face-to-face. Distance education is supported by e-learning tools. Typical e-learning courses define the procedure of teaching. These courses are prepared as a sequence of steps with checkpoints. The aim of checkpoints is to verify whether the student understood the issue and based on it let him move to the next step, or turn him back or recommend him a further study.

The field of study "Business Informatics" with the distance mode of study, which courses are analysed in this paper, is based on combination of regular meetings and e-learning study materials. This field of study does not have its alternative in full-time study, but its curriculum includes courses which are offered within other three fields of study of full-time study mode. The curriculum sets following eight mandatory courses in the first year of study:

- Course A - Information Management,

- Course B - Integration in Information Systems,

- Course C - IT Management,

- Course D - Text Information Processing Methods and Tools,

- Course E - Information Systems Audit,

- Course F - IS/ICT Project Management,

- Course G-Knowledge Discovery in Databases.

- Course H - Business Process Improvement.

E-learning study materials for these courses were created within e-Learning project functionality of the Integrated Study Information System. Each course has its own study material 
that contains both passive (for example texts, presentations, lists of practice exercises, videos) and active (for example quizzes, on-line revision test) learning part. It is a comprehensive information source with a uniform basic structure for each course.

Because a direct teaching is replaced by the study material, it has to be prepared in a manner that leads students to think about explained issues. The study material for distance learning is not a textbook but rather a study guide. The study material has to keep students' attention and provide them continuous feedback, whether they understood the subject well. The study materials are divided into logical units either in accordance with the nature of the subject, or in accordance with the number of tutorials. Study materials have multi-level hierarchical structure, and create a crucial part of the support. They contain annotated interpretation issues, which are realized as a reference to the chapter in the literature, presentations, videos, case studies, assignments for independent work, control issues, etc.

The aim of my analysis was to evaluate the comparability of students' study results with full-time mode of study and analyse an early termination of the study and a usage of interactive elements within study materials.

This analysis attempts to answer the following research questions:

1. Does the early termination of study related to factors such as student's age, attended school, success at the entrance test?

2. To what extent students utilized online tests and lists of control questions?

3. How important were video records of lectures for students?
Most research studies are based on a retrospective evaluation by students and teachers, for example Vostrá Vydrová, $\mathrm{H}$. et al (2012), Šírová E. and Krejčová K. (2011). Analyses, published in this paper, eliminate any subjective evaluation. Analysed data were obtained from several reports of the Integrated Study Information System and the MediaSite tool with video records. Data were obtained in the form of Excel tables from reports of admission procedure, examination reports and lists of statistics about accesses of students to each study material. Information about using of video records was transcribed from statistical reports of the MediaSite tool. Given the small sample of data only simple statistical calculations could be carried out. They were performed in Microsoft Excel software.

\section{Results}

\section{Basis for knowledge comparability}

Knowledge comparability is based on the fact that courses in distance as well as full-time mode of study have identical input assumptions, required and recommended lists of literature, PowerPoint presentations of the topics, requirements for individual work (case studies, essays, knowledge tests) and the final exam. Courses with distance form of study have thirteen weeks of lectures and seminars of full-time mode replaced by three tutorials and the special study material. On the other hand, due to their employment distance students are equipped with a practical experience to help them to understand new information faster and easier. Teachers at the final exam do not distinguish the mode in which the student attended the course. This comparability of output knowledge is evident, if the final exam is in the form of a written knowledge test. 
All mentioned assumptions were met at all courses, which were held in the first academic year 2011/2012, therefore we can compare students' output knowledge on the basis of the final classification grade. The final classification includes evaluation of requirements fulfilment and a final knowledge examination. Results of this analysis are in Table 1.

\begin{tabular}{|c|c|c|c|c|c|c|}
\hline & \multicolumn{2}{|c|}{$\begin{array}{l}\text { Full-time mode } \\
\text { of study }\end{array}$} & \multicolumn{2}{|c|}{$\begin{array}{l}\text { Distance mode } \\
\text { of study }\end{array}$} & \multirow[b]{2}{*}{ 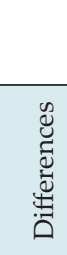 } \\
\hline & & 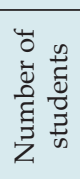 & 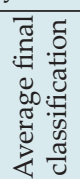 & 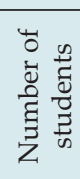 & 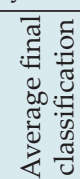 & \\
\hline \multirow{4}{*}{ 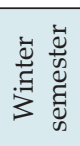 } & Course A & 46 & 2.43 & 17 & 2.41 & 0.02 \\
\hline & Course B & 137 & 2.43 & 18 & 2.11 & 0.32 \\
\hline & Course C & 73 & 2.00 & 19 & 2.11 & -0.11 \\
\hline & Course D & 21 & 2.48 & 19 & 2.32 & 0.16 \\
\hline \multirow{4}{*}{ 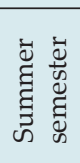 } & Course E & 16 & 1.75 & 14 & 2.43 & -0.68 \\
\hline & Course F & 58 & 2.48 & 17 & 2.35 & 0.13 \\
\hline & Course G & 22 & 1.82 & 17 & 2.00 & -0.18 \\
\hline & Course H & 27 & 2.26 & 16 & 1.88 & 0.38 \\
\hline
\end{tabular}

Table 1: Comparison of the average final classification

The data sample was cleaned before calculating the average classification grade. Data records of students without the grade were excluded from the file therefore student numbers in Table 1 include only students with final classification $1,2,3$ or 4 . It is pleasing, that comparable results were achieved.

From data in table 1 is seen, that only one course of distance students has significantly worse average final classification. On the other hand, this course has among full-time mode of study courses the smallest number of students. Final classifications are comparable for both modes of study.

\section{Early termination of the study}

Students with distance mode of study discontinue the study more often than students with full-time mode of study. Many students are not able to complete their courses because distance education requires self-discipline. Nobody pushes them to study continuously.

Success rate after two semesters of study is shown on Figure 1. From 25 students of distance mode of study, which were admitted to the study in the academic year 2011/2012, eight students terminated the study after the second semester. Positive values on the $\mathrm{Y}$ axis represent the successful completion of the semester (in this case the second one). Negative values on the $\mathrm{Y}$ axis mean the semester of termination. The size of circles corresponds to the number of students with a relevant birth year.

Four of the eight students, who terminated the study, graduate the bachelor's study at the Faculty of informatics and statistics, the rest of them were from other universities. Less successful are students who graduated two and more years before. No relationship to the order based on points from the admission test was detected. 


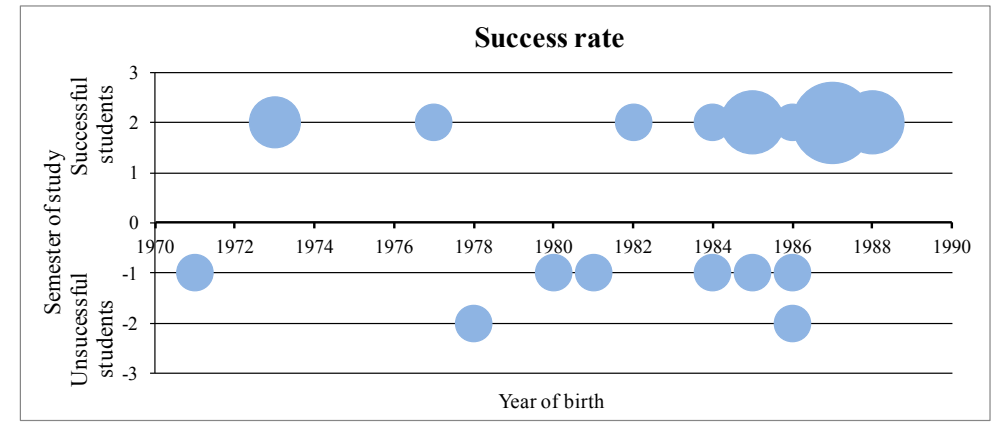

Figure 1: Success rate in view to the year of birthday

\section{Accessing to online tests and lists of control questions}

The second research target was to analyse access rate to online tests, which are available to students with distance mode of study in the e-learning materials. Online tests are interactive elements which aim is to give a feedback to self-study of students. Every test contains different number of questions. Questions are generated from the pre-prepared pool of test questions. Online tests could be repeated without limitations. Student always receives a new variant of the test. Test is evaluated immediately after its submitting. The test evaluation is not recorded, and teachers are not acquainted with it.

The Integrated Study Information System records date and time of all accesses to the e-learning material and its parts. These data are presented in several different outputs, usually shown per student. Available data, which have a different form (graph, table and list) and a level of detail, are accessible only to teachers of the courses and to administrator. From records about each student and the e-learning material for the each course was possible to obtain needed data for analyses. Available data do not contain a length of communication, only date and time when student clicked on an activity. A comparison of learning length would be very difficult even if the date of opening and closing activity would be available. The time spent over the opened activity is influenced by many factors. Also time, during which the student had the activity opened, does not mean that he was engaged in it.

Although basic structure of the e-learning materials is similar, the number of online tests is different. The number of accesses to online tests is showed in Figure 2. The Figure includes only five courses, because the remaining three courses have a very different number of online tests (one, five and seven) and the figure would be confusing. However, from the all data follows that the most often was opened the first test, then the opening of next tests is decreasing during the semester. The number of students, who never opened the tests during the semester, is increasing. Their number is growing average from three to eleven students. It is important to note that the correlation between the final classification and the using of the online tests did not occur.

Other element of a self-study providing feedback to students is a list of control questions. E-learning materials include the list of such questions at the end of each study unit. Questions are used to summarize the subject matter, to prepare for the tutorial and the final exam. The courses contain different numbers of the lists with control questions. Number ranges from one to seven lists. The frequency of accesses to the lists of questions is decreasing during the semester. One or two students, who did not display any list of questions, were in each course. The students were different. The correlation between the final classification and the using of the control lists of questions did not occur. 


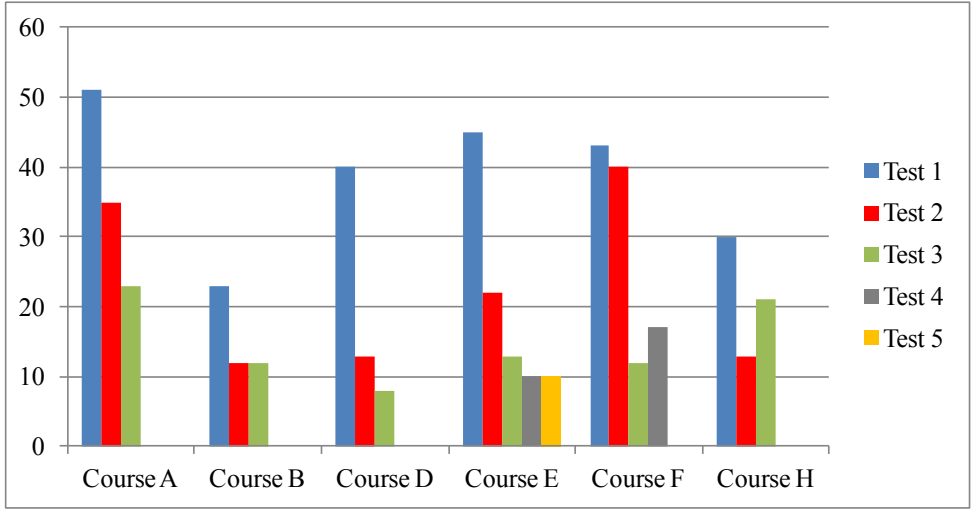

Figure 2: Number of accesses to online tests

\section{Accessing to videos of lectures}

The third part of the research should answer the question, how important were video records of lectures for students. The videos of lectures were taken in the previous academic year. Not all lecturers agreed with the acquisition of videos, therefore videos were available only for four of eight monitored courses. Three of them were prepared for courses in the winter semester, one of them was for a course in the summer semester.

Videos weren't accessible for students with full-time mode of study. The number of videos per course was from nine to twelve (see Table 2). Each video contains a PowerPoint presentation. The course $C$ has doubled the number of lectures against the previous two, therefore duration of all videos is longer and the number of slides is greater. Large number of slides in the course $\mathrm{F}$ is caused by two video records with enormous number of slides (over three hundreds) which contain examples from case studies.

\begin{tabular}{|c|c|c|c|c|c|c|}
\hline & 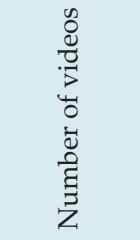 & 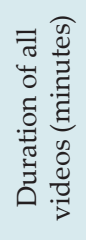 & 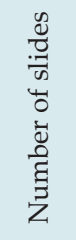 & 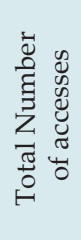 & 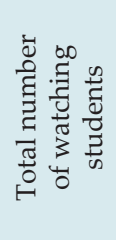 & 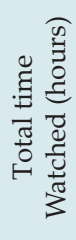 \\
\hline Course A & 12 & 746 & 400 & 491 & 169 & 661 \\
\hline Course B & 11 & 982 & 761 & 264 & 110 & 700 \\
\hline Course C & 12 & 1546 & 1177 & 360 & 119 & 743 \\
\hline Course F & 9 & 742 & 2978 & 118 & 36 & 204 \\
\hline \multirow{4}{*}{$\begin{array}{l}\text { Averages } \\
\text { per } 1 \text { video }\end{array}$} & Course A & 62 & 33 & 41 & 14 & 55 \\
\hline & Course B & 89 & 69 & 24 & 10 & 64 \\
\hline & Course C & 129 & 98 & 30 & 10 & 62 \\
\hline & Course F & 82 & 331 & 13 & 4 & 23 \\
\hline
\end{tabular}

Table 2: Statistics on videos

The main advantage of the videos is that the students can determine day and time when they will watch the lectures. They can track the video faster than was made, move over the video or repeat it. The main disadvantage is that the students cannot communicate with the teacher.

Although distance students did not have lectures, watching videos was not for them so important, as we supposed. None of the students has watched or even opened all available videos for the particular course. Even two video records from course F were not watched at all. 


\section{Discussion}

The low success rate of distance mode of study is presented for instance in Jarkovská et al (2011), only 75\% students in their observed year progressed to the $2^{\text {nd }}$ year of study in the regular way (i.e. without retaking or interrupting the studies etc.). The success rate was even lower in our case, only $68 \%$ students progressed to the $2^{\text {nd }}$ year. Most of unsuccessful students terminated their study already after the first semester (75\%).

Because data sample was small (25 students started the distance study in September 2011 and eight of them have ended their study after the second semester), deeper statistical analysis is not possible. Nevertheless, it seems that younger students are more successful.

Comparison of average final classification confirmed the comparability of output knowledge. Only one course of fulltime students had significantly better average final classification against to distance students in similarly large group. The fulltime mode of study in small group could bring, maybe, better final results, but it would be hardly generally acceptable from society economic point of view.

Higher frequency of accesses to the first test and the list of control questions can be interpreted either by repeating the first tests and list of questions in next months, or by changing learning needs. Because the number of students, who never opened next tests or lists of control questions during the semester, was increasing, the second interpretation is probably more correct.

Balogh et al published (2011) similar results of their analysis. This analysis of accesses to the interactive animations integrated into the e-learning course provided also answer that interactive elements are used by students, but their use is heterogeneous. If final knowledge of students in both forms of study is comparable, heterogeneous access to interactivity elements is not necessarily a negative phenomenon.

Based on frequency of utilizing video records of lectures it could be assumed that it is not the most important source of information from distance students' point of view. This form of compensation of direct teaching is probably sufficiently replaced by e-learning materials.

\section{Conclusion}

Distance education includes methods and technology which let to achieve graduation without daily presence at a school. Distance education should be understood as self-learning supported by special study materials and only six tutorial hours per course during one semester. This paper focuses on the comparability of the output knowledge of students with full-time and distance mode of education. This comparability is based on the fact that students of both forms of study perform the same tasks and tests during the semester and pass the final knowledge exam together.

Students with distance form of study have to be personally motivated to continuous preparation for tutorials and individual homework. Interactive elements within distance study materials create the pressure to continuous learning but also provide feedback to understanding of study topics. Distance students have an important advantage in their experiences from a practice.

The basic analysis confirmed that the output knowledge of students, with a different mode of study, is comparable. Elements of e-learning materials, such as online tests and lists of control questions, played an important role in students' preparation on the tutorials and the final exams. But usage of 
interactive elements had a decreasing trend. Video analysis showed that their watching was a significantly lower than we expected. This trend had a similar development in all courses.

Dependence between the final classification and the frequency of approaches to online tests, control lists of questions or video records did not occur.

The use of selected elements of distance education will be monitored also in the next periods. Larger data sets from multiple periods will enable to perform more detailed analysis and to compare statistical data concerning same courses from several semesters.

\section{Acknowledgements}

This paper was supported by the grant "Advanced Principles and Models for Enterprise ICT Management" under the number P403/10/0092 at the Czech Science Foundation (GAČR).

\section{References}

Balogh, Z., Magdin, M., Turčáni, M. and Burianová, M. (2011) 'Interactivity elements implementation analysis in e-courses of professional informatics subjects', Proceedings of the 8th International Conference on Efficiency and Responsibility in Education (ERIE 2011), Prague, pp. 5 -14.

Carnwell, R. (2000) 'Approaches to study and their impact on the need for support and guidance in distance learning', Open Learning: Journal of Open and Distance Learning, vol. 12, no. 12, pp. 123-140.

Center for Technology in Learning (2010). 'Evaluation of EvidenceBased Practices in Online Learning: A Meta-Analysis and Review of Online Learning Studies', U.S. Department of Education, Office of Planning, Evaluation, and Policy Development, Washington, D.C. pp. 94.

Holmberg, O. (1986) Growth and Structure of Distance Education. London: Croom Helm.

Houška, M., Beránková M. (2011). 'The impact of contact lessons on learning outcomes in mathematics', Proceedings of the 8th International Conference on Efficiency and Responsibility in Education (ERIE 2011), Prague, pp. 93-101.

Jarkovská, M., Kučera, P., Vostrá, H., Varvažovská, P. (2011). 'Comparing Students' Results in Distance-Studies Centres Using Statistical Analyses',Proceedings of the 8th International Conference on Efficiency and Responsibility in Education (ERIE 2011), Prague, pp. 166-177.

Jung, I., Wong, T. M., Li, Ch., Baigaltugs, S. and Belawati, T. (2011) 'Quality Assurance in Asian Distance Education: Diverse Approaches and Common Culture', The International Review of Research in open and distance learning, vol. 12, no. 6, pp. 64-83.

Kunstová, R. (2012) 'Analysis of selected elements of distance education', Proceedings 9th International Conference on Efficiency and Responsibility in Education (ERIE 2012). Prague, pp. 315-322.

MEYS (2012) '1.2 Celkový přehled akreditovaných studijních programů.xls'. Report of the Ministry of Education, Youth and Sports, Prague. Available: http://www.msmt.cz/file/23929 [7 Oct 2012].

Murphy, E., Rodríguez-Manzanares, M.A.(2008)`Contradictions between the virtual and physical high-school classroom: A third-generation activity theory perspective', British Journal of Educational Technology, vol. 39, no.6, pp. 1061-1072. 
Journal on Efficiency and Responsibility in Education and Science

ISSN: 1803-1617, doi: 10.7160/eriesj.2012.050401

Šírová, E. and Krejčová, K. (2011) ‘The Role of the vide interaction guidance in the enrichment of students teachers' social skills', Journal on Efficiency and Responsibility in Education and Science, vol. 4, no. 4, pp. 162-169.

Vostrá Vydrová, H., Jindrová, A. and Dömeová, L. (2012) 'Evaluation of Results in Chosen Subjects and analysis of the Motivation of Distance Student', Journal on Efficiency and Responsibility in Education and Science, vol. 5, no. 1, pp. 3-45. 